\section{Cardiovascular disease surveillance in Mexicans and Mexican Americans: a tale of two countries}

\author{
Ramón Angel Durazo-Arvizu, ${ }^{1}$ \\ Simon Barquera, ${ }^{2}$ \\ Mariana Lazo-Elizondo, ${ }^{3}$ \\ Manuel Franco, ${ }^{3}$ \\ and Richard S. Cooper ${ }^{1}$
}

Suggested citation: Durazo-Arvizu RA, Barquera S, LazoElizondo M, Franco M, Cooper RS. Cardiovascular disease surveillance in Mexicans and Mexican Americans: a tale of two countries. Rev Panam Salud Publica. 2008;23(2):119-24.

Key words: cardiovascular diseases, surveillance, Mexican Americans, Mexico.

\footnotetext{
1 Department of Preventive Medicine and Epidemiology, Loyola University Stritch School of Medicine, Maywood, Illinois, United States of America. Send correspondence and reprint requests to: Ramón Angel Durazo-Arvizu, Associate Professor, Department of Preventive Medicine and Epidemiology, Loyola University Stritch School of Medicine, 2160 S. First Avenue, Building 105, Maywood, IL 60153, United States of America; telephone: (708) 327-9007; fax: (708) 3279009; e-mail: rdurazo@lumc.edu

2 Departamento de Enfermedades Crónicas y Dieta, Instituto Nacional de Salud Pública, Cuernavaca, Morelos, México.

3 Department of Epidemiology, Johns Hopkins Bloomberg School of Public Health, John Hopkins University, Baltimore, Maryland, United States of America.
}

Throughout its history, the United States has consistently received large numbers of immigrants from around the world. Most early immigration originated in Europe, but the more recent influx has been dominated by people from Asia and Latin America (1). In the year 2002, the number of people of Hispanic origin in the United States reached over 37 million (2). The vast majority of this U.S. subpopulation are of Mexican descent (66.9\%), with smaller proportions represented by Central and South Americans (14.3\%), Puerto Ricans (8.6\%), Cubans (3.7\%), and other Hispanics (6.5\%) (2). In March 2003, it was estimated that $53.3 \%$ of the 33.5 million immigrants in the United States were born in Latin America. Two-thirds of those born in Latin America are from Mexico and Central America. Foreign-born Mexicans in the United States currently number 11.9 million $(2,3), 13.6 \%$ of whom entered the country since the year 2000 (3).

The rapid growth of the Hispanic population in the United States has enormous implications for public health. Taken together with substantial migration from Asia, the arrival of over 350000 people per year from Mexico $(4,5)$ requires revision of the current framework used in health-related population research. In the most concrete terms, national health statistics data must now be presented with at least two additional columns for Hispanics and Asians. Embedded in the transition to surveillance for additional racial/ethnic subgroups is a series of complex technical and conceptual challenges. Most prominently, there is an urgent need to understand the significance of the markedly reduced mortality from cardiovascular disease (CVD) among Mexican Americans that is reported by official sources.

Surprisingly, limited effort has been made to understand the evolving health status of this immigrant population within the context of their country of origin. In the absence of highly selective migration, the health status of recent Mexican immigrants should closely resemble that of Mexicans. Due to a substantial investment in surveillance systems over the last decade, nationally representative data are now available from Mexico. It should be possible, therefore, to describe an integrated approach to understanding the burden of CVD among Mexicans and Mexican Americans by comparing results from these national data sources. These data should also be compared to data on other Hispanic subpopulations in the United States, and their respective country of origin. 


\section{Surveillance for CVD}

Surveillance-monitoring and reporting on major health conditions-is a core function of public health care systems, and developed countries have well-established frameworks for carrying it out. Surveillance for CVD, however, presents an unusual set of challenges (6). It requires three main components: (1) tracking of national CVD mortality, (2) monitoring of risk factors, and (3) assessment of the availability and impact of public health interventions and medical care.

Mortality. Cause-specific mortality trends have become the most widely used public health indicator for explaining changes in CVD epidemiology. Despite the potential risk of skewed results from inconsistent death certificate coding, these data are often the only realistic option for true national surveillance of CVD. Other measures of CVD disease occurrence, such as prevalence and incidence, are difficult to estimate accurately within a population because of a high proportion of undiagnosed cases.

Risk factors. Surveys based on representative samples provide the best source of data for monitoring and evaluation of CVD risk factors. Efficient methods exist for obtaining systematic population-wide prevalence rates and global CVD risk estimates based on recurring surveys such as the National Health Survey (Encuesta Nacional de Salud, ENSA) in Mexico (7) and the National Health and Nutrition Examination Survey (NHANES) in the United States (8). These data can also be used to guide public policy and directly inform interventions.

Public health interventions and medical care. Major advances are occurring in CVD clinical care. Therefore, in order to be maximally informative, CVD surveillance must provide information on CVD risk factor detection and control rates as well as treatment and care (e.g., distribution of surgical and catheter-based interventions). While treatment and control rates of hypertension, for example, can be determined from national population surveys, monitoring uptake of hospital-based medical care requires an additional system component for collecting data on individual patients as the frequency of use of cardiac procedures increases.

Over the past several decades, all three components described above have been incorporated in population sampling for European surveillance, known collectively as MONICA (multinational MONItoring of trends and determinants in CArdio- vascular disease). Only limited use has been made of this approach in the United States, however, and no similar studies have been conducted in Mexico.

\section{Secular trends in CVD}

CVD rates are changing rapidly in both industrialized and nonindustrialized countries. The United States, Canada, Australia, and most of Western Europe have all experienced declines in stroke mortality since vital statistics were first recorded in the early $20^{\text {th }}$ century. National data on coronary (ischemic) heart disease (CHD) became available in the United States through changes in death certificate coding in the period after World War II. Steep increases in mortality due to CHD were then observed until 1968, when CHD mortality began to drop sharply (9). A similar decline in CHD was subsequently described in most industrialized countries, including Australia, Canada, and much of Western Europe (10). Since 1968, age-adjusted mortality from stroke has declined almost $75 \%$ in the United States, while CHD has dropped by $60 \%$ (11). It is estimated that approximately one-third to onehalf of this decline is directly related to lower levels of risk factors (12-14). Much of the remaining effect is attributed to better clinical care and tertiary prevention. Achieving reductions in CVD mortality similar to those in the United States is now one of the most important public health challenges facing nonindustrialized countries.

While effective data systems have been developed in most industrialized countries, little is known about the national CVD burden or its related trends in middle-income and poor countries (15). Numerous articles have focused on the growing CVD epidemic in these countries, highlighting the difficulties in implementing effective control strategies when medical care infrastructure is weak. A prerequisite for effective control, however, is adequate surveillance. It is unlikely that substantive, sustainable reductions in the CVD burden will be achieved without better surveillance tools to guide national CVD control strategies, most of which are based on the experiences of industrialized countries. The framework for applying these tools, which correlate trends in risk factors with disease outcomes, has been used to great advantage in many countries $(16,17)$.

Designed to enable similar reductions in the CVD burden among Mexicans and Mexican Americans, the proposals below include suggested lines of research to help define CVD surveillance in these populations, as well as some general demographic and mortality information about the population of Mexican descent to help clarify the nature of the ongoing migration between Mexico and the United States. 


\section{Measuring CVD burden among Mexicans and Mexican Americans}

Mexico has a robust public health system with a high-quality vital registration system; a complex medical care system; and recurrent, nationally representative surveys of risk factors. However, attempts to characterize the CVD epidemic for surveillance purposes, including collection of CVD mortality statistics and surveys of CVD risk factors, have been limited. At present, substantial work is needed to define the validity and consistency of death records and to construct trend lines for major vascular conditions, including heart disease, stroke, and the emerging epidemic of diabetes.

\section{METHODS}

Vital statistics from Mexico, the United States, Puerto Rico, and Cuba were obtained for 5-year incremental age groups and used to calculate age-adjusted mortality rates from cardiovascular disease and diabetes in the various countries. Mortality rates are presented per 100000 population, adjusted to the adult (20-84-year) U.S. population in the year 2000 to facilitate comparisons across time and countries. Direct standardization was applied in all cases (18). Standardization is necessary, given that over $69 \%$ of the adult Mexican population is young (20-44 years old), compared to $51 \%$ in the United States, according to the 2000 census in the respective countries. In addition, $17.7 \%$ of adults in the United States are over the age of 65 , whereas only $8.3 \%$ in Mexico belong to this age group. Based on disease codes from the $10^{\text {th }}$ revision of the World Health Organization (WHO) International Statisti- cal Classification of Diseases and Related Health Problems (ICD-10), mortality is reported for total cardiovascular disease (CVD; ICD I00-I99), including total heart disease (HD; ICD I05-I52), coronary heart disease (CHD; ICD I20-I25), and stroke (ICD I60-I69), as well as diabetes (ICD E10-E14).

\section{RESULTS}

The estimated CVD and diabetes mortality rates are shown in Table 1, based on vital statistics records from Mexico, the United States, Puerto Rico, and Cuba. These figures indicate that in comparison to the general population of the United States, mortality from heart disease in Mexico in the year 2000 was 27\% lower (174 vs. 239 per 100 000, respectively), whereas stroke was 33\% higher (68 vs. 51 per 100 000, respectively). Surprisingly, mortality from diabetes in Mexico for the year 2000 was reported to be almost fivefold higher than in the United States (138 vs. 28 per 100000 , respectively) and is currently listed as the leading cause of death (19).

Table 2 depicts estimated mortality from CVD in the various U.S. subpopulations and in Mexican, Cuban, and Puerto Rican populations. Among men and women in the United States, Mexican Americans have lower mortality rates from total cardiovascular disease-including total heart disease and coronary heart disease - than non-Hispanic whites, African Americans, and Puerto Rican Americans, but higher rates for each of these disease categories than Cuban Americans. Stroke rates among Mexican Americans are lower than those for African Americans, but higher than those for any of the other ethnic groups considered. In addition, women in Mexico have higher rates for total car-

TABLE 1. Age-adjusted mortality rates from cardiovascular disease and diabetes in Mexico and the United States, 2000

\begin{tabular}{|c|c|c|c|c|c|c|c|c|c|c|c|c|}
\hline & \multicolumn{3}{|c|}{ United States } & \multicolumn{3}{|c|}{ Mexico } & \multicolumn{3}{|c|}{ Puerto Rico } & \multicolumn{3}{|c|}{ Cuba } \\
\hline & Men & Women & Total & Men & Women & Total & Men & Women & Total & Men & Women & Total \\
\hline $\begin{array}{l}\text { Heart disease }(105-152)^{\mathrm{b}} \\
\quad \text { Coronary heart disease }\end{array}$ & 283 & 197 & 239 & 174 & 174 & 174 & 224 & 165 & 193 & 230 & 197 & 215 \\
\hline$(120-125)^{b}$ & 212 & 133 & 172 & 126 & 105 & 116 & 151 & 103 & 126 & 182 & 149 & 167 \\
\hline Stroke $(160-169)^{b}$ & 49 & 53 & 51 & 62 & 72 & 68 & 46 & 46 & 46 & 86 & 97 & 92 \\
\hline Total CVD (100-199) & 348 & 262 & 304 & 244 & 255 & 250 & 277 & 216 & 246 & 336 & 318 & 329 \\
\hline Diabetes $(\mathrm{E} 10-\mathrm{E} 14)^{\mathrm{b}}$ & 29 & 28 & 28 & 119 & 157 & 138 & 78 & 82 & 80 & 12 & 26 & 19 \\
\hline $\begin{array}{l}\text { Total mortality from CVD } \\
\text { and diabetes }\end{array}$ & & & 332 & & & 388 & & & 326 & & & 348 \\
\hline
\end{tabular}

a Rates per 100000 population are adjusted to the adult (20-84-year) U.S. population for the year 2000 using the direct standardization method.

b Disease codes from WHO's ICD-10 (International Statistical Classification of Diseases and Related Health Problems, 10th revision). 
TABLE 2. Mortality rates from cardiovascular disease, by gender, ages 20-84, among U.S. subpopulations and among Cuban, Mexican, and Puerto Rican populations, $2000^{\mathrm{a}}$

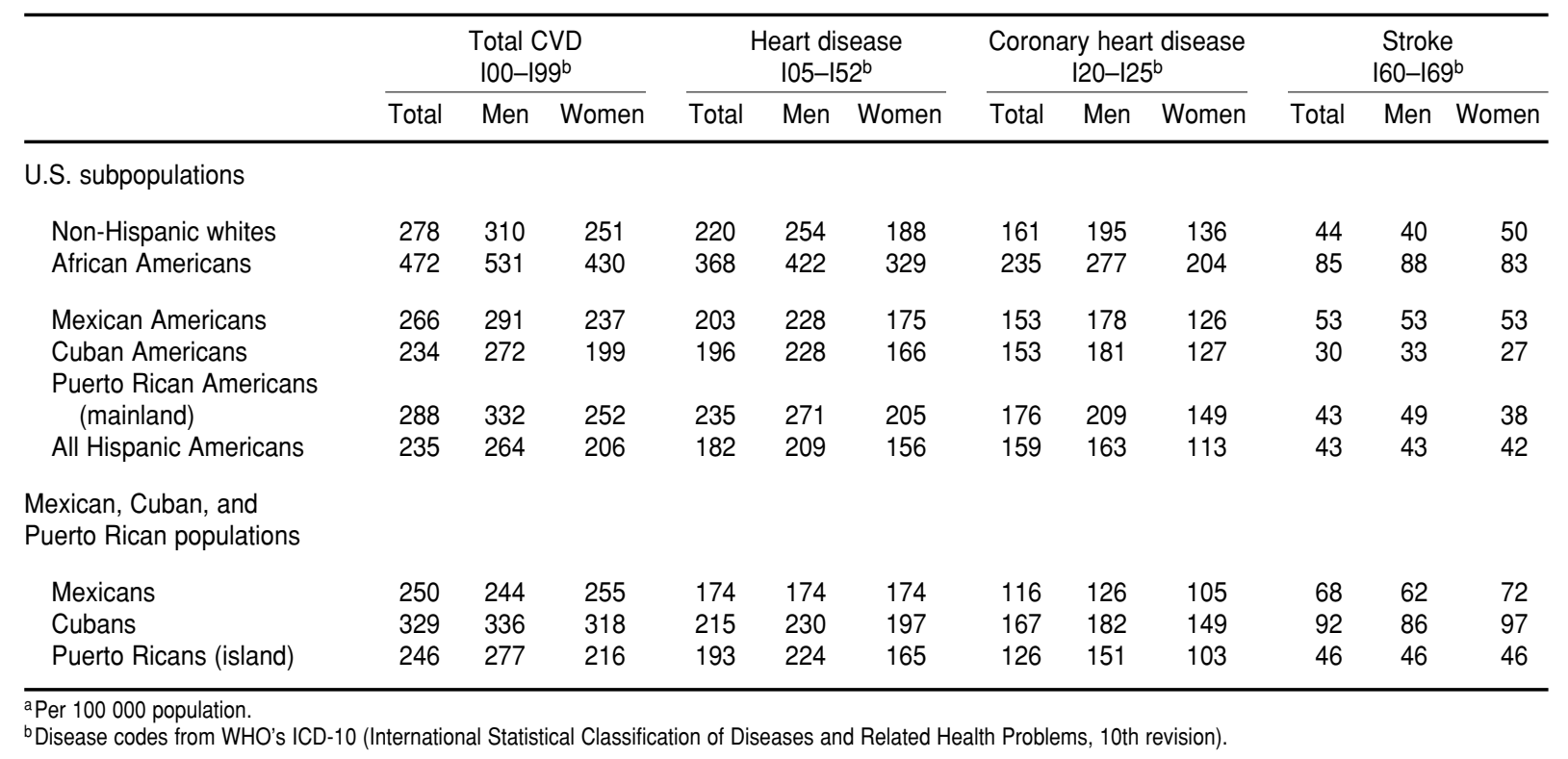

diovascular disease, heart disease, and coronary heart disease than Puerto Rican women, whereas (with the exception of stroke) the opposite is observed among men. Stroke rates are lower among Puerto Ricans than Cubans and Mexicans.

\section{CONCLUSION}

In aggregate, Hispanics are the largest minority population in the United States, and two-thirds of this subpopulation are Mexican Americans. Despite considerable debate, the CVD burden in this population has not been adequately described. At present, it is crucial to obtain reliable information about current levels of CVD and trends. Routine vital statistics data as well as cohort studies based on national samples demonstrate that Hispanic Americans have total mortality rate ratios of approximately 0.65 relative to whites (20-23). However, local studies from Texas suggest Hispanic Americans have higher CVD rates than non-Hispanic whites $(24,25)$. As noted, mortality reports from Mexico suggest lower rates of coronary heart disease but greater mortality from stroke and diabetes compared to the total U.S. population. Because there is usually a one-generation time lag before migrant populations lose the mortality structure of their country of origin, these data raise questions about the validity of Mexican American vital statistics in the United States. Assuming thatwith more consistent death certificate codingstroke can be considered a "sentinel condition," and that the vital records comparison between the United States and Mexico in Table 1 is valid, then the reported rates for stroke among Mexican Americans shown in Table 2 are underestimated by almost $22 \%$ (53 vs. 68 per 100000 ). In this regard, the comparability of the counting systems used to estimate numerators (i.e., deaths) and denominators (i.e., population) needs to be carefully considered. In order to develop an effective CVD control strategy, better surveillance methods will need to be implemented for the Mexican American population.

The most striking feature of the United States-Mexico comparison is the markedly higher mortality ascribed to diabetes in Mexico. These data need to be analyzed within the context of risk factor prevalence rates from the population surveys that document lower diabetes prevalence in Mexico. While these higher mortality rates could reflect, in part, lower levels of medical attention, the discrepancy between prevalence and recorded death rates needs to be explored.

\section{Future directions}

Much of the public health literature in the United States concerning the health status of Latin American immigrants over the past several decades has been organized around the concept of the "Hispanic paradox." This concept grew out of the observation that despite a limited educational background and low occupational status, the health experience of Spanish-speaking immigrants has 
been quite favorable relative to the majority population. This so-called paradox should be viewed with caution, however, as it is apparent that the framework used to define it stems from culturally specific expectations from within the United States, where "low socioeconomic status" is viewed as a powerful and independent negative force determining health experiences. In addition, myriad different cultural practices exist among populations labeled as "Hispanic" in the United States, many of which may have either positive or negative influences on health. Therefore, many questions have been raised regarding the validity of the "Hispanic paradox" $(24,26,27)$. Other approaches for gathering and analyzing data need to be undertaken, however, before this concept is totally dismissed. A suggested alternative approach would focus on the populations of the various countries of origin. Based on the U.S. census for the year 2000 (28), the Latino population can be divided into five main categories: (1) Mexican Americans (59.3\%), by far the largest group, accounting for more than one-third of a million new U.S. immigrants per year; (2) $\mathrm{Cu}-$ ban Americans (3.5\%), an established U.S. subpopulation with limited ongoing migration; (3) Puerto Rican Americans (9.7\%)—despite U.S. citizenship, this group remains distinct from the majority U.S. population due to its ongoing bidirectional migration and retention of Latin American culture; (4) Central Americans (5.1\%), including many persons seeking high-wage employment; and (5) South Americans (4.0\%) and other Hispanics (18.3\%).

It should be noted that various mechanisms rooted in the nature of the economic transitions occurring in specific source countries as a result of globalization could affect CVD patterns in the respective country population. Many societies recently articulated by the global economy exhibit patterns of disease risk that are the inverse of those found in mature capitalist countries (e.g., in Mexico, persons with lower educational level are less likely to smoke cigarettes, which is the inverse of the situation in the United States). Therefore, understanding of CVD patterns among Mexican Americans will be greatly enhanced by taking account of experiences in both the United States and Mexico, as well as the current large-scale migration between the two countries, and by abandoning the use of the category "Hispanic," which aggregates dissimilar population groups.

Much can be learned by viewing the health status of Mexican Americans as the extension and natural evolution of the experience in Mexico. A rigorous characterization of the Mexican migrant population will shed light on their health status and disease burden. Likewise, U.S. public health data extrapolated from CVD monitoring to guide CVD intervention strategies could also be applied to CVD control strategies in Mexico. A first logical step toward integrating the knowledge base from Mexico would be to align existing data systems in the two countries and to describe the underlying patterns of disease outcomes and risk status. The feasibility and effectiveness of the U.S. control strategy could then be evaluated within the Mexican context. To initiate this process, the following lines of research are suggested:

- Describe the health-related characteristics of those migrating from Mexico to the United States;

- Describe the epidemiology of CVD in Mexico, using the country's robust national data sets, which allow for ongoing surveillance of trends;

- Use the knowledge gained from studies in Mexico to shed light on the transitional health status observed among Mexican Americans; and

- Use the information generated by the lines of research suggested above to identify challenges and opportunities that might be useful in defining new policy initiatives to improve cardiovascular health among populations on both sides of the border.

\section{SINOPSIS}

\section{Enfermedad cardiovascular en mexicanos y estadounidenses de ascendencia mexicana: una historia de dos países}

La migración a gran escala que tiene lugar actualmente de México a los Estados Unidos de América origina nuevos retos para la salud pública. Se deben diseñar políticas de salud bien fundamentadas que aborden los problemas emergentes de salud en los estadounidenses de origen mexicano y otras subpoblaciones de los Estados Unidos. En este artículo se describe un enfoque que permite analizar la carga de las enfermedades cardiovasculares (ECV), tanto en mexicanos como en estadounidenses de ascendencia mexicana (en el contexto de la sociedad que acaban de abandonar). Estos datos se analizan también en el contexto de otras poblaciones de ascendencia hispanoamericana. La caracterización rigurosa de la población migrante mexicana permitirá explicar el estado de salud de los estadounidenses de ascendencia mexicana. De manera similar, la copiosa experiencia en salud pública acumulada en los Estados Unidos puede ser útil en la lucha para controlar las ECV en México. El primer paso lógico puede ser alinear los sistemas existentes de datos de los dos países y describir los patrones fundamentales del desenlace y las situaciones de riesgo de la enfermedad.

Palabras clave: enfermedades cardiovasculares, vigilancia, mexicanos americanos, México. 


\section{REFERENCES}

1. Taylor Bell M. Immigration: a megatrends backgrounder. Lexington (KY): The Council of State Governments; 2004

2. Ramirez RR, de la Cruz GP. The Hispanic population in the United States: March 2002. Current Population Reports, P20-545. Washington: U.S. Census Bureau; 2003.

3. Larsen LJ. The foreign-born population in the United States: 2003. Current Population Reports, P20-551. Washington: U.S. Census Bureau; 2004.

4. López DA. Migración en México: datos de 1990 al 2000. Notas Revista de Información y Análysis. 2002;19:45-51.

5. López DA. Migración de mexicanos desde y hacia Estados Unidos de América: estadísticas, problemáticas y retos. Boletín de los Sistemas Nacionales Estadístico y de Información Geográfica. 2004;1(2):21-38.

6. Labarthe DR. Epidemiology and prevention of cardiovascular diseases: a global challenge. Gaithersburg (MD): Aspen Publications; 1998.

7. Olaiz G, Rojas R, Barquera S, Shamah T, Aguilar C, Cravioto P. Encuesta Nacional de Salud 2000. Tomo 2: La salud de los adultos. Cuernavaca, Morelos, México: Instituto Nacional de Salud Pública; 2003.

8. U.S. Department of Health and Human Services, Centers for Disease Control and Prevention, National Center for Health Statistics. National Health and Nutrition Examination Survey (NHANES) 19992004. Hyattsville (MD): US-DHHS-NCHS, 2005.

9. Levi F, Lucchini F, Negri E, La Vecchia C. Trends in mortality from cardiovascular and cerebrovascular diseases in Europe and other areas of the world. Heart. 2002;88(2):119-24.

10. Cooper R, Stamler J, Dyer A, Garside D. The decline in mortality from coronary heart disease, U.S.A., 1968-1975. J Chronic Dis. 1978;31(12):709-20.

11. Cooper R, Cutler J, Desvigne-Nickens P, Fortmann SP, Fiedman L, Havlik R, et al. Trends and disparities in coronary heart disease, stroke, and other cardiovascular diseases in the United States: findings of the National Conference on Cardiovascular Disease Prevention. Circulation. 2000;102(25):3137-47.

12. Goldman L, Phillips KA, Coxson P Goldman PA, Williams L, Hunink MG, et al. The effect of risk factor reductions between 1981 and 1990 on coronary heart disease incidence, prevalence, mortality and cost. J Am Coll Cardiol. 2001;38(4):1012-17.

13. Taylor R, Dobson A, Mirzaei M. Contribution of changes in risk factors to the decline of coronary heart disease mortality in Australia over three decades. Eur J Cardiovasc Prev Rehabil. 2006; 13(5):760-8.

14. Soltero I, Liu K, Cooper R, Stamler J, Garside D. Trends in mortality from cerebrovascular diseases in the United States, 1960 to 1975. Stroke. 1978;9(6): 549-58.

15. Yusuf S, Reddy S, Ounpuu S, Anand S. Global burden of cardiovascular diseases: part I: general considerations, the epidemiologic transition, risk factors, and impact of urbanization. Circulation. 2001;104(22):2746-53.

16. Cheng Y, Chen KJ, Wang CJ, Chan $\mathrm{SH}$, Chang WC, Chen JH. Secular trends in coronary heart disease mortality, hospitalization rates, and major cardiovascular risk factors in Taiwan, 1971-2001. Int J Cardiol. 2005;100(1):47-52.

17. Laatikainen T, Critchley J, Vartiainen E, Salomaa V, Ketonen M, Capewell S. Explaining the decline in coronary heart disease mortality in Finland between 1982 and 1997. Am J Epidemiol. 2005; 162(8):764-73

18. Pagano M, Gauvreau K. Principles of biostatistics. 2nd ed. Pacific Grove (CA): Duxbury; 2000.

19. México, Secretaría de Salud. Estadísticas de mortalidad en México: muertes registradas en el año 2003. Salud Pública Méx. 2005;47:171-187.

20. Liao Y, Cooper RS, Cao G, DurazoArvizu R, Kaufman JS, Luke A, et al.
Mortality patterns among adult Hispanics: findings from the NHIS, 1986 to 1990. Am J Public Health. 1998;88(2): 227-32.

21. Liao Y, Cooper RS, Cao G, Kaufman JS, Long AE, McGee DL. Mortality from coronary heart disease and cardiovascular disease among adult U.S. Hispanics: findings from the National Health Interview Survey (1986 to 1994). J Am Coll Cardiol. 1997;30(5):1200-5.

22. Swenson CJ, Trepka MJ, Rewers MJ, Scarbro S, Hiatt WR, Hamman RF. Cardiovascular disease mortality in Hispanics and non-Hispanic whites. Am J Epidemiol. 2002;156(10):919-28.

23. Thomas AJ, Eberly LE, Neaton JD, Smith GD. Latino risk-adjusted mortality in the men screened for the Multiple Risk Factor Intervention Trial. Am J Epidemiol. 2005;162(6):569-78.

24. Hunt KJ, Resendez RG, Williams K, Haffner SM, Stern MP, Hazuda HP. All-cause and cardiovascular mortality among Mexican-American and nonHispanic White older participants in the San Antonio Heart Study-evidence against the "Hispanic paradox." Am J Epidemiol. 2003;158(11):1048-57.

25. Pandey DK, Labarthe DR, Goff DC, Chan W, Nichaman MZ. Communitywide coronary heart disease mortality in Mexican Americans equals or exceeds that in non-Hispanic whites: the Corpus Christi Heart Project. Am J Med. 2001; 110(2):81-7.

26. Lerman-Garber I, Villa AR, Caballero E. Diabetes and cardiovascular disease: is there a true Hispanic paradox? Rev Invest Clin. 2004;56(3):282-96.

27. Smith DP, Bradshaw BS. Rethinking the Hispanic paradox: death rates and life expectancy for US non-Hispanic white and Hispanic populations. Am J Public Health. 2006;96(9):1686-92.

28. Ramirez RR. We the People: Hispanics in the United States: CENSR-18. (Census 2000 Special Report). Washington: U.S. Bureau of the Census; 2004. 